\title{
The secretion of 5-hydroxytryptamine by a poorly-differentiated bronchial carcinoma
}

\author{
D. J.PARISH, N. CRA W F R D, A N A A. TPENCER \\ From the Department of Pathology and Surgery, University of Birmingham
}

The production of serotonin (5-hydroxtryptamine) and certain related metabolites by tumours associated with the clinical carcinoid syndrome has now been well established. Many of the reported cases have concerned carcinoid tumours of the intestinal tract (Thorson, 1958; Macfarlane, Dalgliesh, Dutton, Lennox, Nyhus, and Smith, 1956) but tumours histologically resembling carcinoids, and also apparently responsible for the carcinoid syndrome or the secretion of serotonin, have been reported from other sites. Of these, the so-called bronchial 'adenomas' are perhaps the commonest (Anlyan, Hargrove, Ruffin, Wallace, Weaver, and Kirshner, 1960; McCormack, McIsaac, Ragde, Groves, and Effler, 1961 ; Warner and Southren, 1958; Sacks and Timme. 1961; Warner, Kirschner, and Warner, 1961 ; Williams and Celestin, 1962). Some of these, like the cases reported by Joseph and Taylor (1960) and by Pollard, Grainger, Fleming, and Meachim (1962), have metastasized widely, have shown a very poorly differentiated histological pattern, and, had they not been associated with the clinical features of the carcinoid syndrome, such as flushing and diarrhoea, might well have been mistaken for undifferentiated bronchial carcinomas. Case 2 of Williams and Azzopardi (1960) was in fact reported as an oat-celled carcinoma.

The purpose of this paper is to describe a patient in whom a poorly-differentiated bronchial carcinoma was shown to produce 5-hydroxytryptamine (5-HT) in considerable quantity although this was not associated with the clinical manifestations of the carcinoid syndrome. This property was discovered by chance during investigations concerning the in vivo metabolism of 5-HT by lung tissue. By a further coincidence, arrangements had been made for the immediate fixation of tumour tissue at the time of operation, which allowed a detailed histological and histochemical examination of the secretory tissue.

\section{CASE REPORT}

A male factory employee aged 51 attended the outpatient department of the United Birmingham Hospitals complaining of pain and numbness of the right side of the face and upper lip during the previous few weeks. The retained root of an upper molar was removed and the 'numbness' was sufficiently severe for this to be done without anaesthesia. There was no improvement in his symptoms, and radiological examination showed an opacity of the right maxillary antrum. Antibiotic treatment produced no improvement and neurological examination showed a right facial nerve palsy with impaired sensation over the right side of the face.

The patient was admitted to hospital for investigation one month after his first visit to the out-patient department and, on direct questioning. he admitted several small haemoptyses during the preceding few months. Clinical examination revealed a right facial nerve palsy, a right-sided perceptive deafness, and slight hypoglossal weakness on the same side. A chest radiograph showed collapse of the left lower lobe with a mass at the left hilum. Bronchoscopy revealed a narrow area in the left lower lobe bronchus well below the origin of the upper lobe bronchus. A biopsy taken at the time showed the features of an 'oat-celled' carcinoma.

By this time (two weeks after admission) there was evidence of widespread involvement of the central nervous system with progressing pyramidal signs in addition to multiple right-sided cranial nerve palsies. These were thought at first to be due to secondary deposits of carcinoma, and the patient was given tretamine ('Triethanomelamine'), $20 \mathrm{mg}$. intravenously in three divided doses, combined with intensive antibiotic therapy. Radiological confirmation of the apparently solitary nature of the lung tumour led to the decision to remove the left lung. A left thoracotomy was performed by Mr. L. D. Abrams, and a tumour $7 \mathrm{~cm}$. in diameter was found in relation to the main left lower lobe bronchus (Fig. 1).

Despite vigorous antibiotic treatment, the postoperative course was complicated by persistent pyrexia and increasing pain in the face. He developed leucopenia (W.B.C. 3,100 per c.mm.) and thrombo- 
cytopenia (12,000 per c.mm.), both of which improved slowly although not completely. When questioned during the post-operative period, he denied having experienced flushes or diarrhoea, and flushing did not occur after he had taken a double whisky shortly before death, which occurred on the tenth postoperative day.

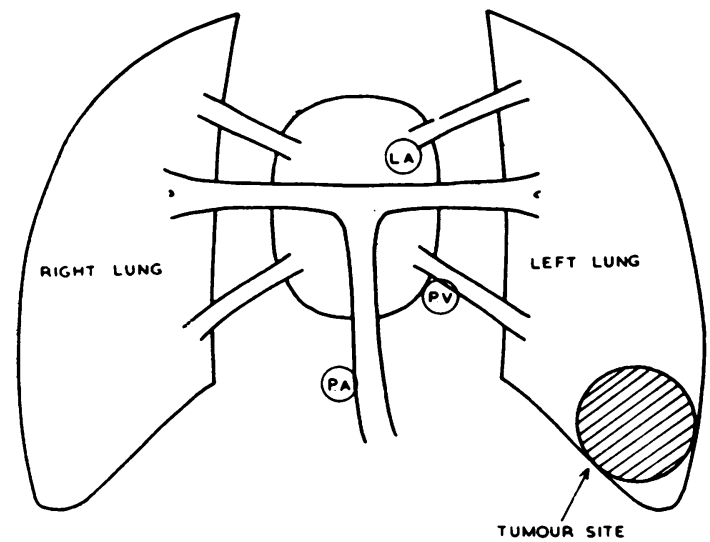

FIG. 1. Diagram showing position of tumour and sites (O) from which blood samples were taken at operation: $P . A$., main common pulmonary artery; $P . V$., pulmonary vein draining affected region in left lung; L.A., left atrium after occluding all vessels of left lung.

\section{BIOCHEMICAL FINDINGS}

During pneumonectomy samples of blood were collected from the main common pulmonary artery, from the left lower pulmonary vein draining the tumour area, and from the left atrium after all the arteries and veins to the left lung had been secured and tied (Fig. 1). It was not possible to obtain a sample direct from a pulmonary vein draining the right (unaffected) lung, but the third sample was regarded as representative of its venous drainage.

All samples were taken into siliconized syringes, and the blood 5-HT levels were determined by a procedure which has been previously described by Crawford and Rudd (1962). Briefly, this method requires light centrifugation of the samples to obtain 'platelet-rich plasma', and the 5-HT content of this fraction is determined spectrophotofluorimetrically. The platelets are then removed from a second aliquot of platelet-rich plasma by highspeed centrifugation, and 5-HT is again estimated in the platelet-free supernatant. By subtraction of these two results, an estimate of the platelet-bound 5-HT fraction is obtained, and a count of the platelets present in the platelet-rich plasma enables this value to be expressed as concentration per unit platelet.
RESULTS (Table I) There is a great increase in the total 'platelet-rich plasma $5-\mathrm{HT}^{\text {' }}$ ' in the blood draining the tumour site when compared with its arterial blood supply. This contrasts with the roughly $50 \%$ decrease in the unaffected lung. The 5-HT produced in the tumour-bearing portion of the lung appears to be present mainly in the free form. There is a slight increase in the plateletbound element, which appears more significant when comparison is made between the venous samples from affected and unaffected areas respectively. The increase in platelet-bound 5-HT also appears when the amount of 5-HT carried by individual platelets is considered (column 5 . Table I).

TABLE I

BLOOD 5-HYDROXYTRYPTAMINE LEVELS IN SAMPLES TAKEN AT PNEUMONECTOMY

\begin{tabular}{|c|c|c|c|c|c|}
\hline \multirow[b]{2}{*}{ Sample Site } & \multicolumn{3}{|c|}{ 5-HT Content (Ng.'ml.) } & \multirow{2}{*}{$\begin{array}{l}\text { P.R.P. } \\
\text { Platelets } \\
\times 10^{6} / \mathrm{ml} .\end{array}$} & \multirow{2}{*}{$\begin{array}{c}\text { Platelet } \\
\text { 5-HT } \\
\text { Ng/109 } \\
\text { Plate- } \\
\text { lets }\end{array}$} \\
\hline & $\begin{array}{c}\text { Total } \\
\text { in } \\
\text { P.R.P. }\end{array}$ & $\begin{array}{c}\text { Free } \\
\text { in } \\
\text { Plasma }\end{array}$ & $\begin{array}{l}\text { Platelet- } \\
\text { bound } \\
\text { Fraction }\end{array}$ & & \\
\hline $\begin{array}{l}\text { Main common pul- } \\
\text { monary artery } \\
\text { Left lower lobe pul- } \\
\text { monary vein } \\
\text { draining affected } \\
\text { region } \\
\text { Left atrium after } \\
\text { occluding left lung } \\
\text { vessels (i.e., ven- } \\
\text { ous drainage nor- } \\
\text { mal lung) }\end{array}$ & 1,357 & 1,170 & 162 & 101 & 2,253 \\
\hline
\end{tabular}

Tumour content $200 \mathrm{Ng}$. 5-HT/g. wet tissue.

Nanogramme (Ng.) $=10^{-9}$ grammes. P.R.P.=Platelet-rich plasma.

These estimations showed that 5-HT was being released into the pulmonary veins draining the tumour site and that most of it appeared as free 5-HT in the plasma. The tumour content of 5-HT was much less than is found in a typical intestinal carcinoid tumour and probably less than is usual in bronchial 'adenomas' of carcinoid type. Pollard et al. (1962) also noted this point, and we agree with them that it probably indicates a low storage capacity for 5-HT by the tumour, but the quantities of 5-HT secreted, although appreciable, were also less than in many carcinoids associated with the clinical syndrome. The possibility of the tumour being a 5-hydroxytryptophan (5-HTP) secretor was excluded by tumour assay, kindly performed for us by Dr. M. Sandler at the Queen Charlotte's Maternity Hospital.

Although no pre-operative urine was available for study, a 24-hour sample collected on the second post-operative day had a total 5-hydroxyindole acetic acid (5-HIAA) content of $16 \mathrm{mg}$. This value was above the accepted normal range (2-9 mg.) but could not be considered raised for 
a post-operative sample in the light of other findings in surgical patients (Crawford and Watts, 1962). Neither 5-HT nor 5-HTP could be detected in the urine by paper chromatographic procedures.

\section{PATHOLOGY}

SURGICAL SPECIMEN The lung was dissected immediately after removal, and thin slices of tissues were fixed at once in buffered formolcalcium acetate. Macroscopic examination revealed a grey tumour mass arising from the posterior bronchus of the lower lobe. It infiltrated the neighbouring lung tissue and extended along the bronchus towards the hilum. A pulmonary artery was infiltrated at one point, and parabronchial and hilar lymph nodes contained deposits of tumour. Elsewhere there were patches of pleural thickening and a fibrous, calcified scar was present at the apex of the lung. Tumour was not seen elsewhere in the lung.

Histological examination of the tumour showed an undifferentiated yet pleomorphic structure similar to that described in 'oat-celled carcinoma' by Azzopardi (1959). The commonest appearance was of sheets of elongated hyperchromatic cells (Fig. 2). In some areas, however, the cells were

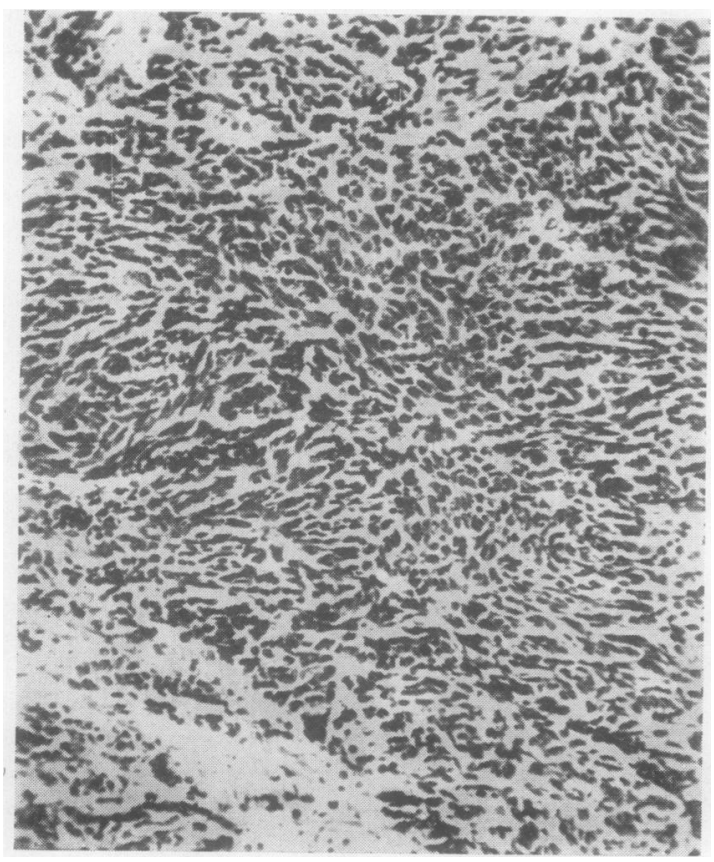

FIG. 2. Tumour composed of sheets of hyperchromatic cells. Haematoxylin and eosin, $\times 150$.

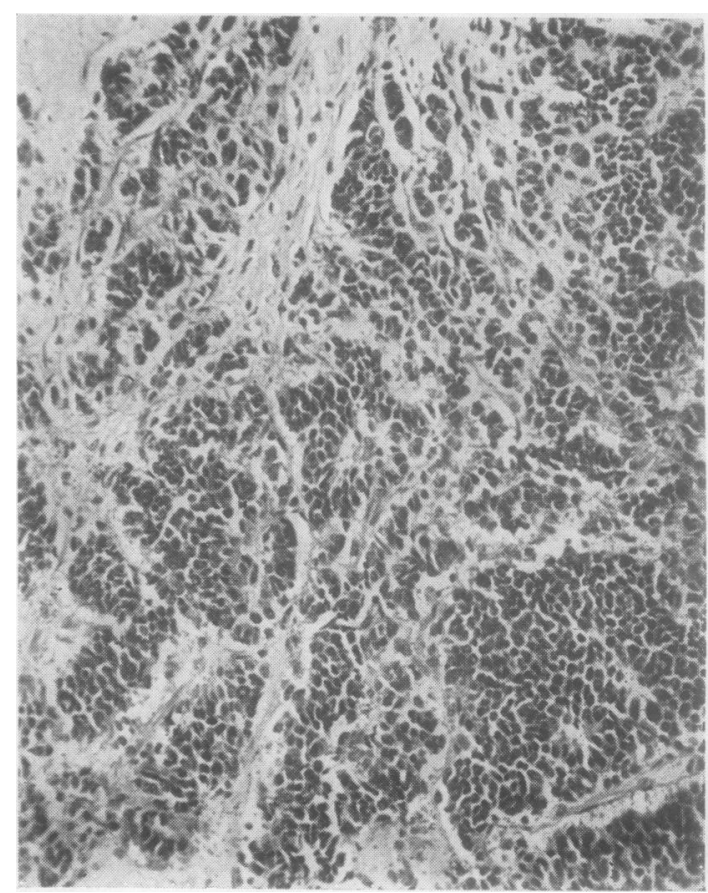

FIG. 3. Portion of tumour showing pseudo-acinar pattern. Haematoxylin and eosin, $\times 150$.

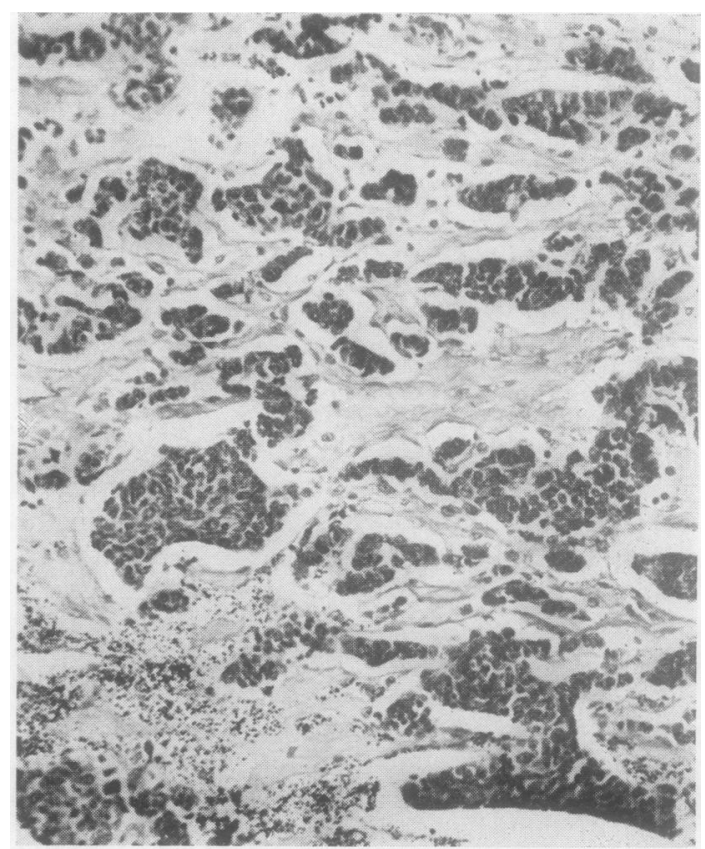

FIG. 4. Well-developed fibrous stroma present in one part of the lung tumour. Iron haematoxylin and Van Gieson's stain, $\times 150$. 


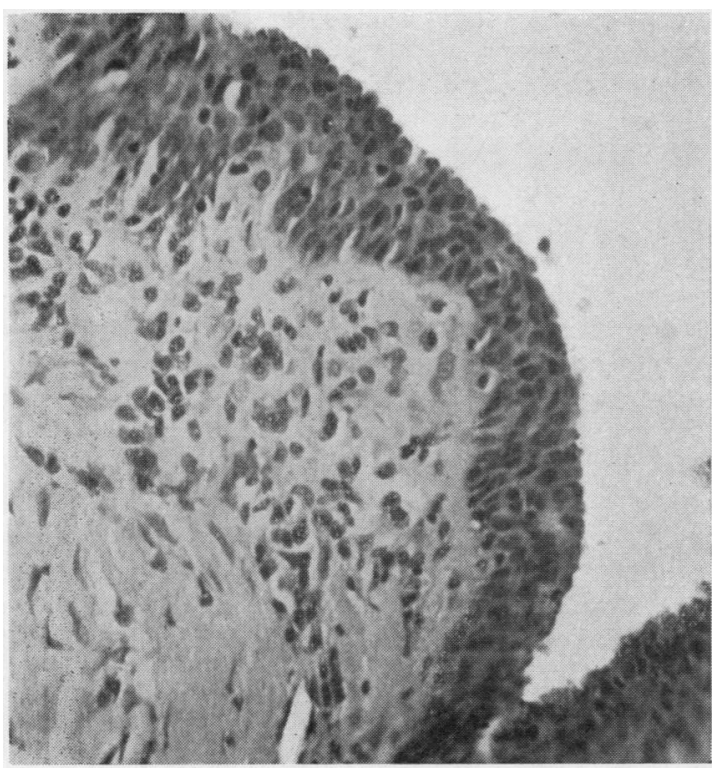

FIG. 5. Squamous metaplasia of bronchial epithelium adjacent to the site of origin of the carcinoma. Haematoxylin and eosin, $\times 250$.

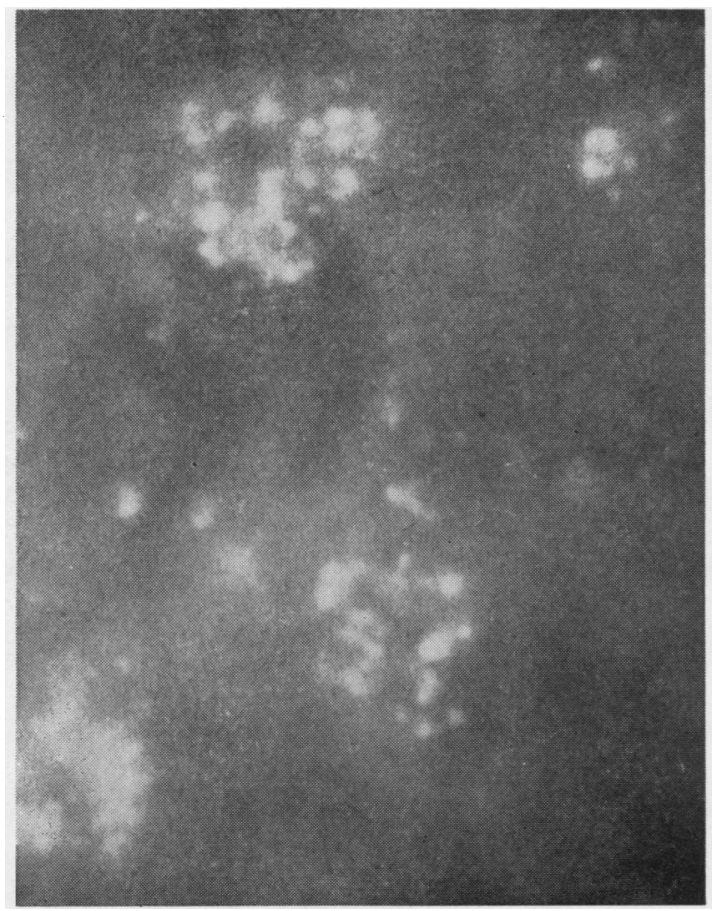

FIG. 6. Tumour cells showing (golden-yellow) autoflourescence in ultra-violet light. plumper and were arranged in a pseudo-acinar pattern (Fig. 3). In other areas there was a welldeveloped fibrous stroma dividing islands of tumour cells (Fig. 4). The tumour appeared to be arising from the bronchial lining in one area, and the surrounding bronchial epithelium showed squamous metaplasia (Fig. 5). Tumour within involved lymph nodes was of a similar histological structure to the main mass.

Histochemical reactions included Schmorl's, Masson's Fontana argentaffin, and Gibbs methods, and a diazo method using fast red salt B. These all failed to show granular material within the tumour cells, although control material from an intestinal carcinoid tumour stained at the same time gave positive results. Deparaffinized sections of the same material from this case and from the control material were mounted in a fluorescentfree medium and examined, without staining, for autofluorescence with a Reichert 'Zetopan' microscope fitted with 'Fluorlux' ultra-violet illumination equipment. Approximately 1 in 10 of the tumour cells showed a vivid, golden-yellow, granular fluorescence of their cytoplasm (Fig. 6). The intensity of fluorescence was as great, if not greater, than that of the control material, although the quantity of reacting material was much less. Fluorescence of an identical colour was obtained by allowing a dilute solution of pure 5-HT to dry on a slide and exposing this to formalin vapour. It was not obtained unless formalin was used.

NECROPSY Necropsy was performed 13 hours after death. There was extensive bronchopneumonic consolidation of the remaining right lung, but tumour was not present. A calcified scar similar to that seen in the left lung was present in the upper lobe. Microscopically, these did not contain tumour and were regarded as healed tuberculous lesions.

Elsewhere in the body there were widespread deposits of tumour. Many of these were multiple, spherical, and typical of metastases, and were seen in liver, pancreas, kidney, and adrenals. Other deposits were present in the skull, maxillary antrum, and ribs. Lymph nodes in the mesentery, porta hepatis, and para-aortic groups were extensively replaced.

There were multiple deposits of tumour in the walls of both small and large intestines. The largest of these was in the upper ileum and measured $1 \mathrm{~cm}$. in diameter. Microscopically tumour was present in all layers of the bowel wall. The overlying mucosa was raised and ulcerated at one point. The other deposits, which were present 
in the submucosa of the lower ileum and colon, were much smaller $(0 \cdot 1$ to $0 \cdot 2 \mathrm{~cm}$. diameter) and covered by intact mucosa. Further tiny deposits were found in the serosa of the intestine and in the peritoneal covering of the diaphragm. A mass of tumour was present in the mesentery adjacent to the largest intestinal deposit.

The brain showed signs of compression with bilateral tentorial herniations. Haemorrhagic tumour was seen in the right temporal lobe and in the basilar part of the pons.

The heart was normal in size, but there was thickening of the anterior cusp of the mitral valve and fusion of adjacent chordae tendineae. The aortic valve cusps were also thickened and adherent. The endocardium lining the cavities of the left atrium and left ventricle appeared normal. Attempts to attribute these lesions to the effects of the tumour secretion were unsuccessful as it was impossible, on histological grounds, to differentiate them from chronic rheumatic valvulitis.

Histological examination of tumour tissue from the various deposits found at necropsy all showed a structure similar to that found in the lung tumour. The histochemical tests were negative, and autofluorescence was either entirely absent or so feeble that differentiation from other tissue elements was uncertain.

\section{DISCUSSION}

The literature dealing with the association between 'bronchial adenoma' and the carcinoid syndrome was referred to by Warner et al. (1961) and discussed recently by Pollard et al. (1962). The latter authors point out that the association is rare and that only a minority metastasize. They refer to the frequent absence of specific histochemical reactions, in particular the absence of argentaffin granules, from these tumours. The illustrations of the histological structure of the case reported by these authors and those of some of the other reported cases are not typical of well-differentiated carcinoid tumours, and cases reported by Williams and Azzopardi (1960) and by Harrison, Montgomery, Ramsey, Robertson, and Welbourn (1957) suggest that tumours with the histological structure of undifferentiated or 'oat-celled' carcinoma may also be associated with the carcinoid syndrome. The latter case also demonstrated the features of Cushing's syndrome.

We are convinced that, in the case which we have described, the lung tumour was a primary bronchogenic carcinoma. The solitary nature of this tumour, with a demonstrable site of origin from bronchial epithelium which showed sur- rounding squamous metaplasia, in the presence of $\underset{\overrightarrow{0}}{\vec{\rho}}$ multiple, widely dispersed tumour deposits else- $\bar{O}$ where in the body, seems to us to substantiate 듬 this view. The occurrence of secondary deposits in $\frac{\overline{\bar{T}}}{\overline{7}}$ the intestine is unusual in bronchial carcinoma, $\mathbb{\mathscr { D }}$ and the largest of these had appearances which could not be distinguished from a primary in- $s$ testinal tumour. It may be that this (and possibly? some of the other deposits) were poorly differentiated primary carcinoid tumours, but this view ${ }_{\sigma}^{\omega}$ would only imply that they were of a multifocal $\overrightarrow{\vec{z}}$ origin and would not detract from our belief that the bronchial carcinoma had arisen locally.

In the absence of biochemical evidence of 5-HT $\vec{\sigma}$ secretion and granular autofluorescence, this $N$ tumour would certainly have been regarded as an $\mathrm{O}$ ordinary undifferentiated bronchial carcinoma. Autofluorescence of tumour cells has been described in bronchial adenoma by Williams and Azzopardi (1960). Our failure to demonstrate this property in the necropsy tissues from the present $\vec{\imath}$ case suggests that either the use of buffered $\stackrel{\odot}{\varnothing}$ formalin fixative or the immediate fixation of thin : slices of tissue was responsible for the unmistakable results obtained with the tissue removed at operation. That immediate fixation is an important factor is supported by the evidence of Barter and Pearse (1955), who showed that the argentaffin $\varnothing$ reaction may be impaired by delay.

The blood levels of 5-HT, both free and platelet-bound, in patients with the carcinoid syndrome are highly variable. In two other patients, in whom the primary tumour was believed to be of bronchial origin, normal systemic blood levels 0 were recorded despite high urine 5-HIAA output $\stackrel{\otimes}{\times}$ and the presence of symptoms such as flushing $\dot{\sigma}^{-}$ and diarrhoea. Conversely, in certain other patients in whom the primary tumour was of $\frac{0}{0}$ intestinal origin, very high blood levels have been found with only moderately increased urine 의 5-HIAA output. Factors such as tissue binding $D$ and the rate of destruction by amine oxidase at various sites in the body, the multiplicity, site, and $\bar{N}$ magnitude of distant metastases and the capacity $O$ of the platelets for 5-HT transport may all con- $N$ tribute to the presence and severity of the clinical $\underset{\omega}{N}$ symptoms.

The amount of 5-HT liberated into the circulation by the bronchial tumour in the present $\frac{}{\Phi}$ case was much less than may occur with intestinal $\stackrel{\rho}{?}$ carcinoid tumours, ${ }^{1}$ but there must also have been $\square$

1 In four carcinoid patients (of proven intestinal origin), all of $\frac{O}{D}$ whom flushed spontaneously to a moderate or severe degrce and $\triangle$ also had liver enlargement and diarrhoea $(5-20+/$ day), the blood $\vec{D}$ 5-HT levels ranged between the following limits: platelet-bound $\varrho$ serotonin $\left(\mathrm{Ng} . / 10^{\circ}\right.$
$(\mathrm{Ng} / \mathrm{ml}$ )
$50-300$. 
present an efficient de-aminating mechanism elsewhere in the body since the blood returning to the lung through the pulmonary artery had a much lower content. This is even more remarkable if it is considered that the tumours outside the lung also probably secreted 5-HT.

Fluorescence microscopy is scarcely a routine diagnostic method. Even if it were applied to the examination of bronchial carcinomas fixed in the usual way, it would probably not reveal the special nature of tumours of the type described in this paper. Apart from biochemical estimations on blood samples taken at operation, there is no other method of identifying such tumours, and it seems likely that some at least of cases regarded as undifferentiated bronchial carcinomas may be of this type. One of us has now performed similar chemical estimations of 5-HT in pulmonary arterial and venous blood samples in 15 cases of bronchial carcinoma without encountering another similar case. It seems therefore that secretion of 5-HT is a rare property of undifferentiated bronchial carcinoma. On the present evidence we are unable to say whether this property denotes a special type of tumour. It is possible that the secretion of 5-HT may prove to be a property which will serve to differentiate tumours on a pathogenic or aetiological basis, and we provisionally regard the tumour which we have described as an undifferentiated type of bronchial carcinoid. In the absence of evidence of the tissue of origin of these tumours, however, it is not possible to decide whether they are to be regarded as a separate group, distinct from other bronchial carcinomas.

\section{SUMMARY}

A poorly-differentiated bronchial carcinoma occurring in a 51-year-old man was found by chemical assay to secrete 5-hydroxytryptamine. although the carcinoid syndrome was not present.

A proportion of the tumour cells contained autofluorescent granules, but other histochemical reactions for enterochromaffin granules were negative.

\section{REFERENCES}

Anlyan, W. G., Hargrove, Jr., M. D., Ruffin, J. M., Wallace, D. K. Weaver, W. T., and Kirshner, N. (1960). Metastasizing bronchial adenoma. Occurrence in patient with the functioning carcinoid syndrome. J. Amer. med. Ass., 174, 415.

Azzopardi, J. G. (1959). Oat-cell carcinoma of the bronchus. J. Path. Bact., 78, 513.

Barter, R., and Pearse, A. G. E. (1955). Mammalian enterochromaffin cells as the source of serotonin (5-hydroxytryptamine). Ibid., 69,
25 .

Crawford, N., and Rudd, B. T. (1962). A spectrophotofluorimetric method for the determination of serotonin (5-hydroxytryptamine) in plasma. Clin. chim. Acta, 7, 114.

- and Watts, G. T. (1962). Excretion of 5-hydroxy indolyl-acetic acid after surgery. Nature (Lond.), 195, 182.

Harrison, M. T., Montgomery, D. A. D., Ramsey, A. S., Robertson, J. H., and Welbourn, R. B. (1957). Cushing's syndrome with carcinoma of bronchus and with features suggesting carcinoid tumour. Lancet, 1, 23.

Joseph, M., and Taylor, R. R. (1960). Argentaffinoma of the lung with carcinoid syndrome. Brit. med. J., 2,568 .

McCormack, L. J., McIsaac, W. M., Ragde, H., Groves, L. K., and Effler, D. B. (1961). " Functioning"' pulmonary neoplasms : I. The carcinoid tumor. II. The hemangiopericytoma. Cleveland Clin. Quart., 28, 145.

Macfarlane, P. S., Dalgliesh, C. E., Dutton, R. W., Lennox, B., Nyhus, L. M., and Smith, A. N. (1956). Endocrine aspects of argentaffinoma with special reference to the use of urinary 5 -hydroxyindoleacetic acid estimations in diagnosis. Scot. med. J., $1,148$.

Pollard, A., Grainger, R. G., Fleming, O., and Meachim, G. (1962) • An unusual case of metastasising bronchial "adenoma" associated with the carcinoid syndrome. Lancet, $2,1084$.

Sacks, M. I., and Timme, A. H. (1961). Metastasizing bronchial adenoma with associated carcinoid syndrome. Brit. J. Cancer, $15,722$.

Thorson, $\AA$. H. (1958). Studies on carcinoid disease. Acta med. scand. Suppl., 161, 334.

Warner, R. R. P., Kirschner, P. A., and Warner, G. M. (1961). Serotonin production by bronchial adenomas without the carcinoid syndrome. J. Amer. med. Ass., 178, 1175.

Warner, R. R. Pichel, and Southren, A. L. (1958). Carcinoid syndrome produced by metastasizing bronchial adenoma. Amer. J. Med., 24, 903.

Williams, E. D., and Azzopardi, J. G. (1960). Tumours of the lung and the carcinoid syndrome. Thorax, 15, 30 .

- and Celestin, L. R. (1962). The association of bronchial carcinoid and pluriglandular adenomatosis. Ibid., 17, 120. 